\title{
Situational antecedents to organizational identification and the role of supervisor support
}

\author{
Matthew Valle \\ Martha and Spencer Love School of Business, Elon University, Elon, \\ North Carolina, USA \\ Martha C. Andrews \\ Cameron School of Business, University of North Carolina Wilmington, \\ Wilmington, North Carolina, USA, and \\ K. Michele Kacmar \\ McCoy College of Business Administration, Texas State University, \\ San Marcos, Texas, USA
}

\begin{abstract}
Purpose - The purpose of this paper is to examine the effects of procedural justice, training opportunities and innovation on job satisfaction and affiliation commitment via the mediating effect of organizational identification. The authors also explored the moderating role of satisfaction with supervisor on the relationship between the antecedents and organizational identification as well as its moderating effect on the mediational chain.

Design/methodology/approach - The authors used structural equation modeling techniques, using MPLUS 7.4, to analyze data collected from 247 full-time employees who were recruited by undergraduate students attending a private university in the Southeast region of the USA.

Findings - Results demonstrated that the indirect effects for procedural justice and training opportunities as predictors were significant, while none of the paths for innovation as a predictor were significant. Satisfaction with supervisor moderated the relationships between procedural justice and organizational identification and innovation and organizational identification.

Originality/value - This research expands the nomological network concerning antecedents and consequences of organizational identification. It also explores the role of satisfaction with one's supervisor, as this can affect identification with the organization. This research provides support for the notion that stronger employee-organization relationships lead to positive individual and organizational outcomes.
\end{abstract}

Keywords Job satisfaction, Training, Organizational identification, Procedural justice, Commitment

Paper type Research paper

Research has consistently demonstrated that stronger employee-organization relationships lead to positive attitudinal and behavioral outcomes (He \& Brown, 2013; Riketta, 2005). Organizational identification (OID) is seen as central to understanding those relationships

(C) Matthew Valle, Martha C. Andrews and K. Michele Kacmar. Published in Organization Management Journal. Published by Emerald Publishing Limited. This article is published under the Creative Commons Attribution (CC BY 4.0) licence. Anyone may reproduce, distribute, translate and create derivative works of this article (for both commercial and non-commercial purposes), subject to full attribution to the original publication and authors. The full terms of this licence may be seen at http://creativecommons.org/licences/by/4.0/legalcode 
OMJ

17,3

154

(Ashforth \& Mael, 1989). Individuals who identify with their organization are more likely to work hard for the organization, are less likely to be absent, and are less likely to leave the organization (Ashforth, Harrison, \& Corley, 2008; Dutton, Dukerich, \& Harquail, 1994; Riketta, 2005). Employees whose sense of self is tightly connected to the social status and organizational prestige which the employing organization conveys are more satisfied and more involved in their jobs (He \& Brown, 2013). This cognitive linking (Dutton, Dukerich, \& Harquail, 1994) between the organization and the self is generally seen as the key to ensuring organizational effectiveness (Pratt, 1998).

The practical implications of increased OID among an organization's employees are clear. Organizations can expect to reap the benefits of a more highly engaged workforce through increased citizenship behaviors and higher levels of organizational support (Ashforth \& Mael, 1989; Edwards, \& Peccei, 2007). More fundamentally, increased OID causes individuals to exert greater effort on organizationally appropriate tasks that generate value (e.g. increased employee creativity: Hirst, van Dick, \& van Knippenberg, 2009) while decreasing the incidence of behaviors which destroy value (e.g. the costs associated with turnover: Author, 2006). Framed in this way, the job of creating and maintaining a sense of connection between employees and organizations has become a leadership challenge (Scott \& Stephens, 2009) as well as a leadership imperative.

Therefore, the purpose of this study is to investigate the impact of procedural justice, training opportunities and innovation on job satisfaction and affiliation commitment via the mediating effect of OID. Our intent here is to focus on the work environment or situational antecedents to OID which have not yet received sufficient attention in the OID literature. Additionally, we incorporate the moderating effect of satisfaction with the supervisor to further explore the nature of the environment in which identification is either enhanced or modulated.

\section{The mediating effect of organizational identification}

OID is conceptualized as the "perception of oneness with or belongingness to" the organization (Ashforth \& Mael, 1989, p. 34), and generally as a congruence of organizational and individual values (Pratt, 1998). Based on social identity theory (Haslam, 2004; Tajfel \& Turner, 1986), OID posits that individuals classify themselves into different social categories to locate their place in the social environment (Stinglhamber, Marique, Caesens, Desmette, Hansez, Hanin et al., 2015). The model presented in Figure 1 positions OID as the center of our conceptualization of the relationships between the antecedents and outcomes in the

Figure 1. Hypothesized model

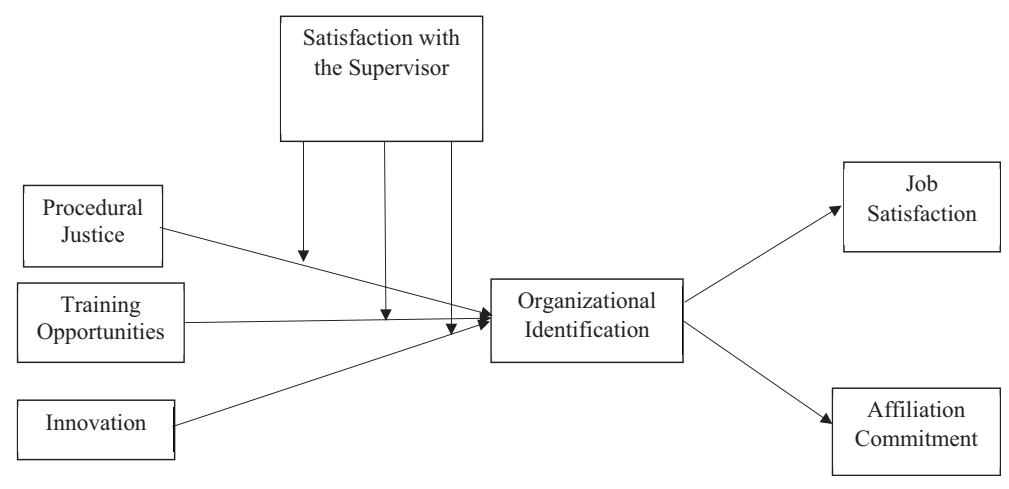


model. We do this for two reasons. First, Ashforth and Mael (1989) suggest that understanding OID is central to understanding the relationships between antecedents and individual attitudinal and behavioral outcomes. The implication that OID is a cognitive linking mechanism is supported by Bandura's $(1986,1989)$ work in social cognitive theory. Bandura suggested that human behavior is regulated by forethought, such that cognitions about actions and potential outcomes help shape the level, direction and persistence of effort on tasks. Bandura's concept of emergent interactive agency (1986) suggests that people make conscious and reciprocal contributions to action by considering their motivations in light of various antecedents and outcomes. Additionally, Dutton and Dukerich (1991) suggest that OID is deeply dependent on perceptual (cognitive) processes - the more attractive an organization's image, the stronger the identification. Second, although Meyer, Becker and Van Dick (2006) review research that supports three perspectives on the relationship between identification and commitment (that identification is synonymous with commitment, a greater whole of which commitment is a part, or an antecedent of commitment), we believe that OID and affective commitment are indeed distinct, and that OID is an antecedent of affective commitment (Bergami \& Bagozzi, 2000; Meyer et al., 2006; Riketta, 2005; Stinglhamber, Marique, Caesens, Desmette, Hansez, Hanin et al., 2015). Therefore, we position OID as a mediator in our model.

\section{Situational antecedents to organizational identification}

Previous research investigations of OID antecedents included analyses of OID attributes (Dukerich, Golden, \& Shortell, 2002), leadership factors (Carmeli, Atwater, \& Levi, 2011), and social exchange factors (Blader \& Tyler, 2009), among others (He \& Brown, 2013). Among the correlates of OID in Riketta's (2005) meta-analysis were those related to demographics (e.g. tenure, age, job level, gender, education). He and Brown (2013) suggest that dispositional differences in OID development is also under-researched. We believe that the inclusion of certain environmental and situational factors affecting OID is overdue. Specifically, we investigate the effects of procedural justice, training opportunities and an innovative culture on OID and its outcomes.

Procedural justice refers to the perceptions an employee has about the policies and procedures administered by an organization and whether they have a voice in the process (Konovsky, 2000). Employees can form these perceptions through daily interactions with their supervisors. Procedural justice has been found to motivate employee cooperative behavior and enhance job-related performance (Aryee, Chen, \& Budhwar, 2004). Procedures that are perceived to be fair should increase employee perceptions of attachment and identity. Because individuals are generally motivated by self-enhancement needs, they tend to identify with organizations that confer positive qualities upon them (Dutton, Dukerich, \& Harquail, 1994).

One of the mechanisms discussed by Fuller, Hester, Barnett, Frey, Relyea and Beu (2006) that acts as a signal to employees that they are valued is the development of high commitment management (HCM) practices within organizations. HCM practices include recognition, opportunities for training/development, participation in decision-making and problem-solving and pay for performance (Fuller, Hester, Barnett, Frey, Relyea, \& Beu, 2006). In this research, we focus on one particular HCM practice: opportunities for trainings/ development. The extent to which individuals believe that the organization provides developmental opportunities for growth should be a tangible reminder that the organization values the individual's contribution (Allen, Shore, \& Griffeth, 2003). Such programs provide the employee with opportunities to develop their skills and knowledge and communicate that the organization is willing to invest in the employee (Allen, Shore, \& Griffeth, 2003). As 
$\mathrm{OMJ}$ 17,3

a signal indicating that the employee is a valued member of the organization, the availability of training/development opportunities should serve to increase identification with the organization (Reade, 2001).

And finally, external prestige is a significant contributor to self-concept orientations (Hameed et al., 2013; He \& Brown, 2013) and OID, as individuals tend to identify more with organizations perceived as important and prestigious by external stakeholders (Fuller, Hester, Barnett, Frey, Relyea, \& Beu, 2006). The group engagement model (Tyler \& Blader, 2003) suggests that people evaluate their status in a group, in part, based on the perspective of those outside the group. Fuller, Hester, Barnett, Frey, Relyea and Beu (2006) suggest that organizational visibility and prestige is based upon characteristics (e.g. size, growth, distinctiveness) that are likely to result in the organization having a "publicly recognized name.” (p. 820). Organizations which are distinctive via their success with innovation (e.g. meeting innovation goals, Fuller, Hester, Barnett, Frey, Relyea, \& Beu, 2006) would appear to provide more visibility, status and prestige to their employees. Therefore, we believe that an organization which fosters a culture of innovation is attempting to provide something distinctive which may be reflected by external agents as conferring greater status or prestige on organizational participants. Consistent with this perspective, Vijayakumar and Padma (2014) examined four types of cultures for their impacts on OID. The culture that was most strongly related to OID was adhocracy cultures. These cultures are characterized by innovation and risk taking and can be further described as entrepreneurial in nature. Members of these organizations are free to experiment and challenge the current ways of doing things. Given this discussion, we hypothesize the following:

H1. OID mediates the relationship between procedural justice and job satisfaction and affiliative commitment.

H2. OID mediates the relationship between training opportunities and job satisfaction and affiliative commitment.

H3. OID mediates the relationship between innovation and job satisfaction and affiliative commitment.

\section{The moderating effect of satisfaction with the supervisor}

Satisfaction with the supervisor may enhance perceptions of support and OID in the context of effective procedural justice mechanisms, training opportunities and innovation initiatives. Immediate supervisors are considered the most influential in the daily work lives of their employees. They communicate expectations, provide rewards and training opportunities, and communicate policies and procedures (Kim, Hur, \& Jun, 2017). DeConinck and Stilwell (2004) argued that those who feel they have been treated fairly and have voice will experience a higher level of satisfaction with their supervisors. In their study, perceptions of procedural justice were strongly related to satisfaction with one's supervisor across two data sets (DeConinck \& Stilwell, 2004). Employee perceptions of training have been linked with satisfaction with supervisors as well. Schmidt (2007) found that those who are satisfied with workplace training report higher levels of overall job satisfaction, including satisfaction with one's supervisor. He highlighted the importance of training in attracting quality applicants as well as predicting overall job satisfaction and influencing career decisions. Finally, satisfaction with one's supervisor has been positively related to innovative organizations (Chen, Lee, Tsui, \& Yu, 2012). In an examination of the cosmetics industry, Chen, Lee, Tsui and Yu (2012) found that climates that are innovative, open and flexible are highly correlated with satisfaction with one's supervisor. They stressed the 
importance of supervisors in building and supporting innovative climates. Therefore, we predict when satisfaction with the supervisor is high, the job context factors previously discussed will be more strongly and positively related to OID:

\section{Role of supervisor support}

H5. Satisfaction with the supervisor moderates the indirect relationships between procedural justice, training opportunities and innovation and job satisfaction through OID such that these relationships are stronger when satisfaction with supervisor is high.

H6. Satisfaction with the supervisor moderates the indirect relationships between procedural justice, training opportunities and innovation and affiliation commitment through OID such that these relationships are stronger when satisfaction with supervisor is high.

\section{Method}

Participants

Subjects (full-time employees) were recruited by undergraduate students attending a private university in the Southeast region of the USA. Thirty-four students were asked to provide contact information (name, email address) of no more than ten family and friends who were at least 21 years of age and who worked full-time (i.e. $35 \mathrm{~h}$ or more per week). Each student submitted ten names/contact information; each potential participant was then sent an email invitation with a link to the survey. In exchange for their help in recruiting subjects, students received a nominal amount of course credit. This method of data collection has been successfully used in several studies (Liu, Perrewé, Hochwarter, \& Kacmar, 2004; Treadway, Hochwarter, Kacmar, \& Ferris, 2005).

To ensure the integrity of the data, we found and excluded erroneous cases. For instance, respondents who self-reported their age below 21 years of age were eliminated as were respondents who provided the same response ("flat lining") across $65 \%$ or more of the survey. In addition, respondents who took less than six minutes to complete the survey were dropped. We included several "attention check" questions (e.g. "The answer to this question is 2.") to confirm that the participants were reading the questions. We removed all cases in which the participants did not respond correctly to these questions. In all, 247 of 340 individuals responded to the electronic invitation and successfully completed the survey instrument ( $72 \%$ yield rate).

A total of $56 \%$ of the respondents were female and $76 \%$ were Caucasian. The majority $(59 \%)$ were at least 36 years of age and $42 \%$ had worked for their organization at least five years.

\section{Materials}

Unless otherwise noted, the items in the measures described below were scored using a fivepoint scale $(5=$ high and $1=$ low):

- Procedural justice. We assessed procedural justice using the seven-item measure ( $\alpha=0.82$ ) developed by Colquitt (2001). We asked participants to refer to the procedures their immediate supervisor uses to make decisions about pay, rewards, evaluations, promotions, assignments, etc., and to respond on a scale where 1 = "to a 
$\mathrm{OMJ}$

17,3

\section{8}

small extent" and 5 = "to a large extent." A sample item is "To what extent can you influence the decisions arrived at by those procedures?"

- Training opportunities. We used the five-item measure $(\alpha=0.91)$ developed by Hung-Wen (2013), as adapted by Taormina (1994), to capture organizational training opportunities. A sample item is "This organization has provided excellent job training for me."

- Innovation. We used the nine-item measure $(\alpha=0.86)$ developed by Dobni (2008) to assess organizational innovation. A sample item is "We have an innovation vision that is aligned with projects, platforms, or initiatives."

- Satisfaction with supervisor. We used Hatfield, Robinson and Huseman's (1985) measure of satisfaction with supervisor. This measure included four items $(\alpha=0.88)$ with anchors that denoted high and low supervisor qualities (e.g. Unfriendly/Friendly).

- $O I D$. We used the six-item measure $(\alpha=0.84)$ developed by Mael and Ashforth (1992) to capture OID. A sample item is "This organization's successes are my successes."

- Job satisfaction. We used Cammann, Fichman, Jenkins, and Klesh's (1983) three-item $(\alpha=0.85)$ measure of job satisfaction. A sample item is "All in all, I am satisfied with my job."

- Affiliation commitment. We used a three-item measure $(\alpha=0.75)$ developed by Balfour and Wechsler (1996) to assess affiliative commitment. A sample item is "I feel a strong sense of belonging to this organization."

\section{Procedure}

Using MPLUS 7.4, we used structural equation modeling techniques to analyze our data. We began by estimating a measurement model. Second, we reran the model after adding an uncorrelated method factor to the measurement model to analyze the impact of common method variance in our study. Next, we added paths to the measurement model to estimate the fully mediated model shown in Figure 1 to test for indirect effects. Finally, we added satisfaction with supervisor as a first stage moderator and estimated the model again to test for interactive effects.

\section{Results}

The means, standard deviations and correlations among the variables used in our study are shown in Table 1 . As expected, the variables in our study were positively correlated, but none of the correlations exceeded 0.60 .

Table 1.

Correlations, standard deviations and descriptive statistics for variables of interest

\begin{tabular}{|c|c|c|c|c|c|c|c|c|}
\hline Variable & Mean & $\mathrm{SD}$ & 1 & 2 & 3 & 4 & 5 & 6 \\
\hline 1. Procedural justice & 3.69 & 0.77 & & & & & & \\
\hline 2. Training opportunities & 3.65 & 0.83 & $0.31^{* * * *}$ & & & & & \\
\hline 3. Innovation & 3.58 & 0.62 & $0.41^{* * * *}$ & $0.42^{* * * *}$ & & & & \\
\hline 4. Organizational identification & 3.82 & 0.68 & $0.42^{* * * *}$ & $0.31^{* * * *}$ & $0.24^{* * * *}$ & & & \\
\hline 5. Satisfaction with the supervisor & 4.11 & 0.92 & $0.56^{* * * *}$ & $0.45^{* * * *}$ & $0.34^{* * * *}$ & $0.38^{* * * *}$ & & \\
\hline 6. Job satisfaction & 3.90 & 0.74 & $0.49^{* * * *}$ & $0.36^{* * *}$ & $0.28^{* * * *}$ & $0.48^{* * * *}$ & $0.47^{* * * *}$ & \\
\hline 7. Affiliation commitment & 3.75 & 0.74 & $0.46^{* * *}$ & $0.37^{* * * *}$ & $0.24^{* * *}$ & $0.56^{* * * *}$ & $0.59^{* * * *}$ & $0.55^{* * *}$ \\
\hline \multicolumn{9}{|c|}{ Notes: $N=247 ;{ }^{*} p<0.05 ;{ }^{* * *} p<0.01 ; * * * * 0.001$} \\
\hline
\end{tabular}


Our first step was to estimate a measurement model to confirm that our scales demonstrated discriminant validity. The model fit the data $\left(X^{2}(608)=1005, \mathrm{CFI}=0.97, \mathrm{TLI}=0.97, \mathrm{RMSEA}=\right.$ $0.051, \mathrm{SRMR}=0.065)$ and all path loadings were significant. Given the way our data were collected, we next tested for common method variance by adding an uncorrelated method factor to the measurement model. According to Williams, Cote, and Buckley (1989), if model fit is significantly improved with the addition of an uncorrelated method factor, common method variance may be of concern. The fit statistics after adding an uncorrelated method factor improved only slightly $(\mathrm{CFI}=0.98$, TLI $=0.98$, RMSEA $=0.041$, SRMR $=0.056)$. However, the chi-square difference test between these two models indicated a significant difference $\left(X^{2}\right.$ diff $(37)$ $=421, p<0.05$ ). Based on the significant chi-square test, we next calculated the variance explained by the method factor by summing the squared loadings. In our case, common method variance accounted for $10 \%$ of the total variance which is much smaller than the $25 \%$ observed by Williams, Cote and Buckley (1989). Overall, the results of the common method variance analyses suggest that the measurement model does benefit from the addition of an uncorrelated method factor, but the gain in fit is quite small, and more importantly the method factor appears to account for little variation in the data.

Following Muthén's (2004) recommendation, we next added paths to our measurement model to estimate the fully mediated model shown in Figure 1 prior to testing for moderation. As suggested by Taylor, MacKinnon and Tein (2008), we used a bias corrected bootstrapping approach to determine the significance of the indirect effects in our models (Shrout \& Bolger, 2002). Results for the indirect effects are shown in Table 2. As can be seen there, the indirect effects for procedural justice and training opportunities as predictors were significant, while none of the paths for innovation as a predictor were significant. Thus, $H 1 a, H 1 b, H 2 a$ and $H 2 b$ were supported, while $H 3 a$ and $H 3 b$ were not.

In our final step, we added satisfaction with supervisor as a first stage moderator and reestimated the model. As can be seen in Figure 2, two of the interactions were significant. Thus, $H 4 b$ was not supported. To determine if the form of the significant interactions aligned with our predictions, we graphed the significant interactions. In Figure 3, while both relationships between procedural justice and OID are positive, simple slope analyses revealed that the high satisfaction with supervisor line is stronger $(t=4.50, p<0.00)$ than the low satisfaction with supervisor line $(t=2.55, p<0.05)$. Thus, $H 4 a$ was supported. Turning to Figure 4 we see that only the slope for the low satisfaction with supervisor line is significant (low $t=2.37, p<0.05$ high $t=0.70, p=0.49$ ). Thus, $H 4 c$ was supported.

\begin{tabular}{|c|c|c|c|c|}
\hline \multirow[b]{2}{*}{ Path } & \multirow{2}{*}{$\begin{array}{c}\text { Indirect } \\
\text { effect }\end{array}$} & \multirow[b]{2}{*}{$p$} & \multicolumn{2}{|c|}{$95 \% \mathrm{CI}$} \\
\hline & & & Low & High \\
\hline Procedural justice $\rightarrow$ Organizational identification $\rightarrow$ Job satisfaction & 0.28 & 0.00 & 0.16 & 0.41 \\
\hline $\begin{array}{l}\text { Training opportunities } \rightarrow \text { Organizational identification } \rightarrow \text { Job } \\
\text { satisfaction }\end{array}$ & 0.13 & 0.00 & 0.04 & 0.21 \\
\hline Innovation $\rightarrow$ Organizational identification $\rightarrow$ Job satisfaction & 0.02 & 0.64 & -0.08 & 0.12 \\
\hline $\begin{array}{l}\text { Procedural justice } \rightarrow \text { Organizational identification } \rightarrow \text { Affiliative } \\
\text { commitment }\end{array}$ & 0.34 & 0.00 & 0.21 & 0.46 \\
\hline $\begin{array}{l}\text { Training opportunities } \rightarrow \text { Organizational identification } \rightarrow \text { Affiliative } \\
\text { commitment }\end{array}$ & 0.15 & 0.00 & 0.05 & 0.25 \\
\hline $\begin{array}{l}\text { Innovation } \rightarrow \text { Organizational identification } \rightarrow \text { Affiliative } \\
\text { commitment }\end{array}$ & 0.03 & 0.64 & -0.09 & 0.15 \\
\hline
\end{tabular}

Notes: $N=247$. Confidence intervals not containing 0 are significant

Table 2. Indirect effects 
OMJ

17,3

\section{0}

Finally, we explored the moderated mediation results shown in Table 3. The indirect effect from procedural justice to job satisfaction through OID when satisfaction with supervisor was high was 0.43 and 0.18 when low. Further, the difference between these two effects was significant $(0.24, p<0.01)$ indicating a significant strengthening of the indirect effect when individuals worked for a supervisor with whom they were satisfied. A similar effect was found for the indirect effect from procedural justice to affiliative commitment through OID. The indirect effect when satisfaction with supervisor was high was 0.56 and 0.24 when low. Again, the difference between these effects was significant $(0.32, p<0.01)$ indicating a strengthening in the indirect effect when satisfaction with one's supervisor was high. Thus, $H 5 a$ and $H 6 a$ were supported. As none of the other moderated mediation results were significant, no support was found for $\mathrm{H} 5 b, \mathrm{H} 6 \mathrm{~b}, \mathrm{H} 5 \mathrm{c}$ or $\mathrm{H} 6 \mathrm{c}$.

Figure 2.

Completely

standardized solution
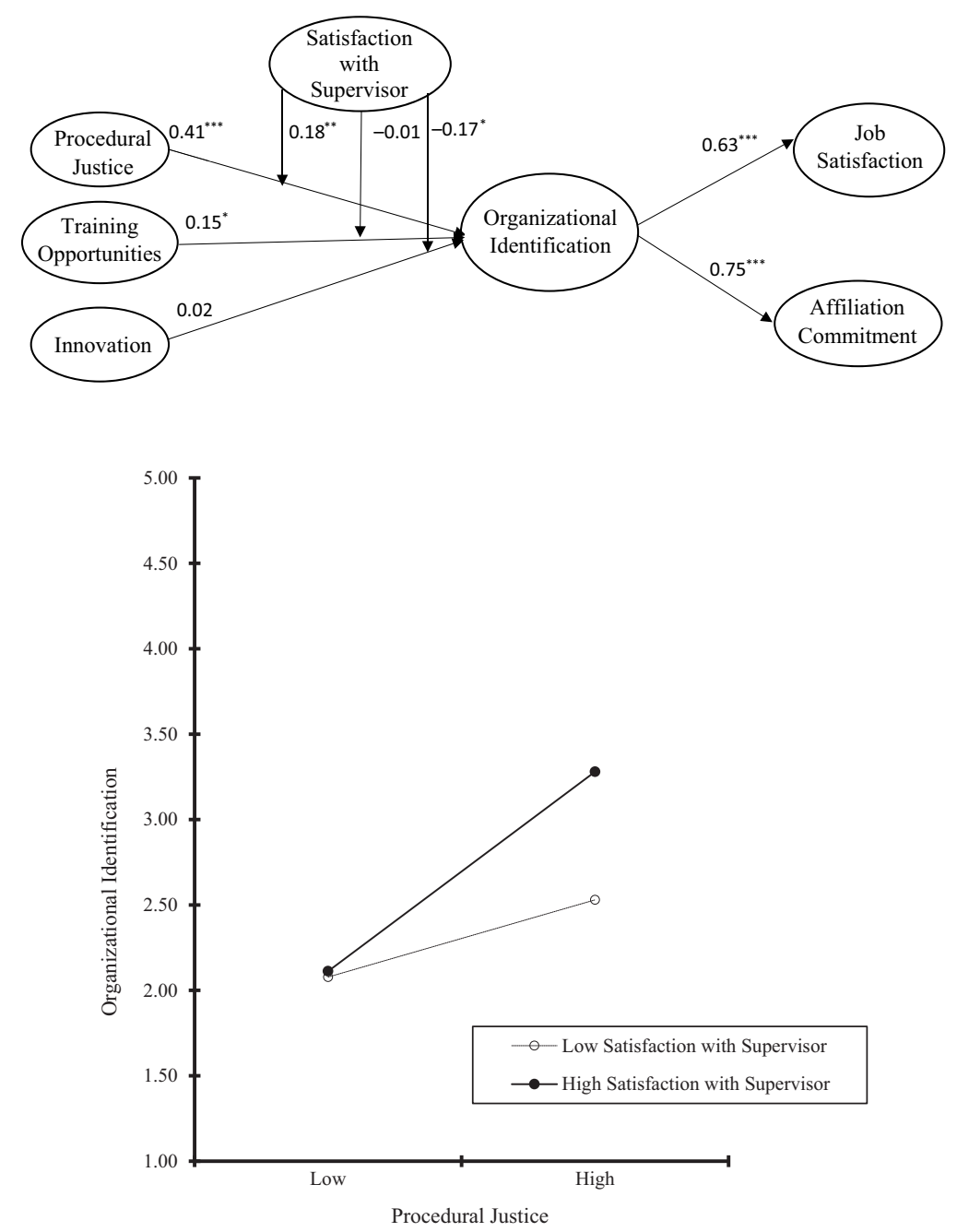

Procedural Justice
Figure 3.

Interactive effect of satisfaction with supervisor on the relationship between procedural justice and organizational identification 


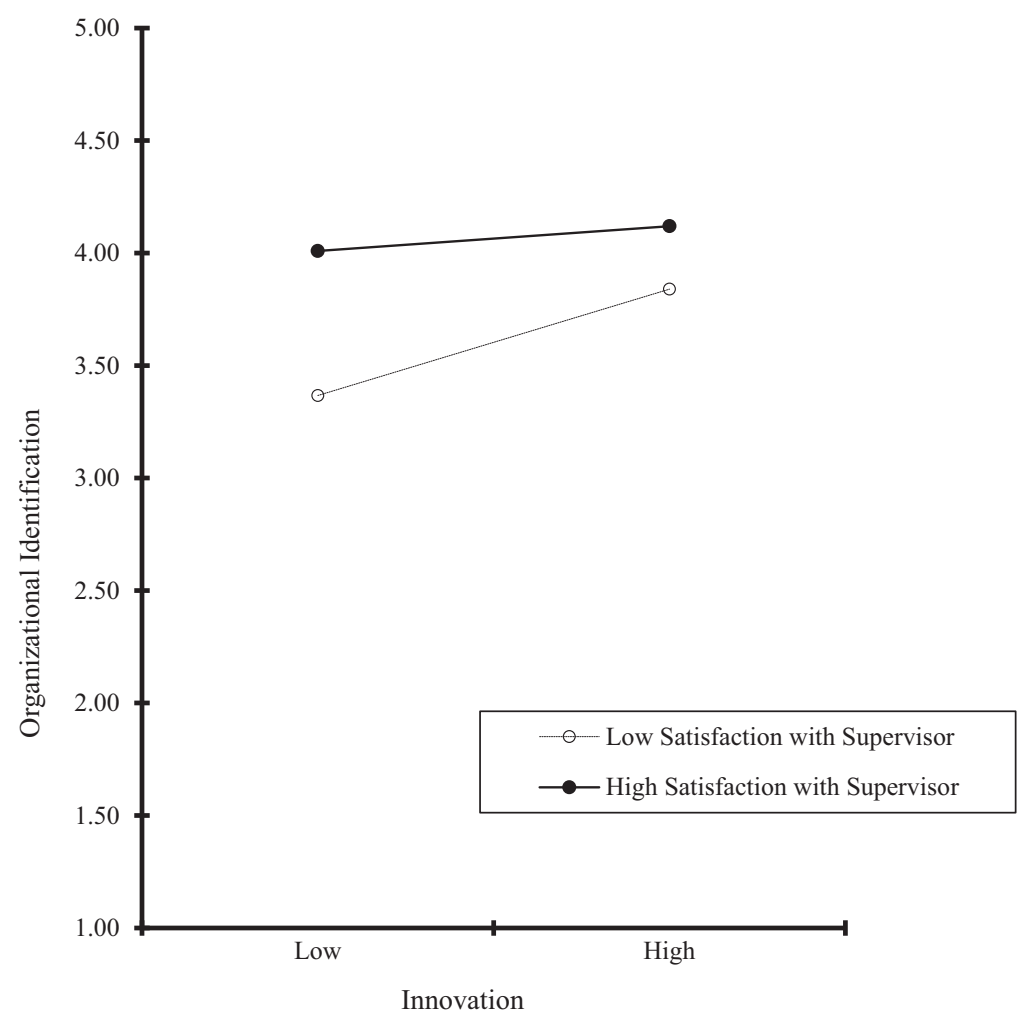

161

Figure 4.

Interactive effects of satisfaction with supervisor on the relationship between innovation and organizational identification

\section{Discussion}

The purpose of this study was to examine the effects of procedural justice, training opportunities and innovation on job satisfaction and affiliation commitment via the mediating effect of OID. Our intent was to focus on the work environment or situational antecedents to OID which have not yet received sufficient attention in the OID literature. If identification with the organization is indeed a good thing, organizations which take steps to ensure that organizational procedures and processes are fair and equitable, and training opportunities plentiful, will increase OID and the subsequent satisfaction and commitment of employees. Additionally, supervisors who work with employees to build positive, supporting relationships will find enhanced identification as a result. To the extent that increased OID ultimately and positively impacts top line growth while reducing the costs of dysfunctional turnover, the structuring of job context to support procedural justice perceptions and employee training would seem to be useful interventions.

There are several strengths of this research that bear mentioning. First, this research advances theory in a meaningful way by integrating OID as a mediator and including a new moderator in a model of OID. By confirming full mediation of procedural justice and training opportunities (job context factors) on job satisfaction and affiliation commitment through the influence of OID, we offer support for OID as a useful cognitive linking variable between individual perceptions of identity/self-worth and outcomes. We also believe that the data analytic approaches undertaken by this research provide confidence in our results and 


\section{$\mathrm{OMJ}$ 17,3}

Path

\begin{tabular}{ccc}
$\begin{array}{c}\text { Indirect } \\
\text { effect }\end{array}$ & \multicolumn{2}{c}{$95 \%$ CI } \\
Low & High \\
\hline
\end{tabular}

High satisfaction with supervisor

Procedural justice $\rightarrow$ Organizational identification $\rightarrow$ Job satisfaction

Training opportunities $\rightarrow$ Organizational identification $\rightarrow$ Job satisfaction

$\begin{array}{rrrr}0.43 & 0.00 & 0.23 & 0.62 \\ 0.08 & 0.10 & -0.02 & 0.19 \\ -0.17 & 0.17 & -0.40 & 0.07 \\ & & & \\ 0.56 & 0.00 & 0.31 & 0.81 \\ & & & \\ 0.11 & 0.09 & -0.02 & 0.24 \\ -0.22 & 0.16 & -0.52 & 0.09\end{array}$

\section{2}

Innovation $\rightarrow$ Organizational identification $\rightarrow$ Job satisfaction

Procedural justice $\rightarrow$ Organizational identification $\rightarrow$ Affiliative

commitment

Training opportunities $\rightarrow$ Organizational identification $\rightarrow$ Affiliative commitment

Innovation $\rightarrow$ Organizational identification $\rightarrow$ Affiliative commitment

\section{Low satisfaction with supervisor}

Table 3.

Conditional indirect effects
Procedural justice $\rightarrow$ Organizational identification $\rightarrow$ Job satisfaction

Training opportunities $\rightarrow$ Organizational identification $\rightarrow$ Job satisfaction

Innovation $\rightarrow$ Organizational identification $\rightarrow$ Job satisfaction

Procedural justice $\rightarrow$ Organizational identification $\rightarrow$ Affiliative

commitment

Training opportunities $\rightarrow$ Organizational identification $\rightarrow$ Affiliative commitment

Innovation $\rightarrow$ Organizational identification $\rightarrow$ Affiliative commitment

$\begin{array}{rrrr}0.18 & 0.03 & 0.01 & 0.35 \\ 0.09 & 0.08 & -0.01 & 0.20 \\ 0.22 & 0.13 & -0.06 & 0.51 \\ & & & \\ 0.24 & 0.02 & 0.04 & 0.45 \\ & & & \\ 0.12 & 0.08 & -0.02 & 0.26 \\ 0.29 & 0.11 & -0.06 & 0.65\end{array}$

Notes: $N=247 . \mathrm{CI}=$ confidence interval. Confidence intervals that contain 0 are not significant

conclusions. We investigated the validity of our measurement instruments and analyzed the relational structure of our model and the factor structure of our measurement scales. We also tested for common method variance (CMV) using a procedure outlined by Williams, Cote, and Buckley (1989).

Among the limitations of our research is the fact that we used both supervisor and organizational referents for the independent variables in our model. This was done for two reasons. First, the procedural justice scale used the supervisor as the referent, so we did too. The procedural justice items were designed around the "procedures used by employees' supervisors in making such decisions" (Colquitt, 2001, p. 395) and much of the procedural justice research uses the supervisor as referent (De Cremer \& Sedikides, 2005; Scott \& Colquitt, 2007). Although the supervisor is the referent, he/she is the conveyor of organizational policies (Naumann \& Bennett, 2000). The essential determinant of procedural justice is whether the employee has voice in the decision-making process and feels as though the outcome can be influenced (Thibaut \& Walker, 1975). Second, we wanted variety in the referent of our predictors to ensure alignment with our outcomes as one was at the individual level (job satisfaction) and other was at the organizational level (affective commitment).

We failed to find an effect for innovation as a predictor of OID. Perhaps our measure of innovation did not adequately capture the extent to which organizational prestige due to innovation and/or an innovative culture was reflected in our subject's identification with the organization. An additional limitation is that our data were collected by self-report. It would have been beneficial to temporally separate the predictor and criterion variables to reduce CMV, but as we performed a post hoc analysis to rule out CMV, we are confident that the model relationships as investigated are robust. We also understand that there may be multiple ways in which satisfaction with supervisor could be causally involved in the process (as opposed to being a moderator, as we propose in our model). It is also possible to hypothesize reversed paths in our model. As a post hoc robustness check, we estimated a 
reversed paths model in which the independent variables became the dependent variables and vice versa. This model fit significantly worse than the hypothesized model $\left(\Delta X^{2}(2)=\right.$ $23.43, p<0.001$ ). Therefore, while the hypothesized model presents just one representation of how the constructs could be theoretically related, our post hoc analysis offers additional support for this model. And finally, while we believe that the high response rate is a significant strength of this research and may be due to the strong personal relationship between the faculty/research team member and the students who recruited participants, it is equally likely that the opportunity to earn extra credit contributed to the strong response.

\section{Role of supervisor support}

163

\section{Conclusion}

Research has consistently demonstrated that stronger employee-organization relationships lead to positive individual and organizational outcomes. Our results confirm the central and important role that supervisors play in enhancing subordinate identification with the organization. As has been demonstrated in prior research, individuals who identify with their organization are more likely to work hard for the organization, are less likely to be absent and are less likely to leave the organization. In this research, we found that individuals who identify with their organization will also be more satisfied and more committed to their work. These are all positive and valued outcomes, and OID is seen as central to understanding those relationships. We also found that perceptions of fairness (procedural justice) and training opportunities for employees enhance OID.

Given the changing nature of the employment contract, and the rise of a more contingent workforce, the days of binding employees to the organization for life long since passed. However, the goal of enhancing OID should not be to develop great employees for the long term, but to develop great employees for however long they choose to stay with the organization. Given these new labor market realities, organizations which work to provide positive, supportive, and fair environments for employees will attract the best employees both short and long term. If there is such a thing as a sustainable competitive advantage for human resource leaders in organizations, it might just be in developing systems and processes to support and enhance OID regardless of which individuals occupy organizational positions. Great organizations are composed of great people, but great people often come and go. Perhaps, then, what makes organizations great is that they continue to attract and develop great people. Building identification with the organization would seem to be a useful place to start that process.

\section{References}

Allen, D. G., Shore, L. M., \& Griffeth, R. W. (2003). The role of perceived organizational support and supportive human resource practices in the turnover process. Journal of Management, 29(1), 99-118. Retrieved from https://doi.org/10.1177/014920630302900107

Aryee, S., Chen, Z. X., \& Budhwar, P. S. (2004). Exchange fairness and employee performance: an examination of the relationship between organizational politics and procedural justice. Organizational Behavior and Human Decision Processes, 94(1), 1-14. Retrieved from https://doi. org/10.1016/j.obhdp.2004.03.002

Ashforth, B. E. \& Mael, F. A. (1989). Social identity theory and the organization. Academy of Management Review, 14(1), 20-39. Retrieved from https://doi.org/10.5465/amr.1989.4278999

Ashforth, B. E., Harrison, S. H., \& Corley, K. G. (2008). Identification in organizations: an examination of four fundamental questions. Journal of Management, 34(3), 325-374. Retrieved from https://doi. org/10.1177/0149206308316059

Author. (2006). Sure everyone can be replaced. . .but at what cost: Turnover as a predictor of unit-level performance. Academy of Management Journal, 49(1), 133-144. Retrieved from https://doi.org/ 10.5465/amj.2006.20785670 
$\mathrm{OMJ}$ 17,3

Bandura, A. (1986). Social foundations of thought and action: a social cognitive theory, Englewood Cliffs, NJ: Prentice-Hall.

Bandura, A. (1989). Human agency in social cognitive theory. American Psychologist, 44(9), 1175-1184. doi: 10.1037/0003-066X.44.9.1175.

Bergami, M. \& Bagozzi, R. P. (2000). Self-categorization, affective commitment and group self-esteem as distinct aspects of social identity in the organization. British Journal of Social Psychology, 39(4), 555-577. Retrieved from https://doi.org/10.1348/014466600164633

Blader, S. L. \& Tyler, T. R. (2009). Testing and extending the group engagement model: Linkages between social identity, procedural justice, economic outcomes, and extrarole behavior. Journal of Applied Psychology, 94(2), 445-464. Retrieved from https://doi.org/10.1037/a0013935

Cammann, C., Fichman, M., Jenkins, D., \& Klesh, J. (1983). Assessing the attitudes and perceptions of organizational members. S. Seashore, E. Lawler, P. Mirvis, \& C. Cammann, (Eds), Assessing organizational change: a guide to methods, measures, and practices, New York, NY: John Wiley.

Carmeli, A., Atwater, L., \& Levi, A. (2011). How leadership enhances employees' knowledge sharing: the intervening roles of relational and organizational identification. The Journal of Technology Transfer, 36(3), 257-274. Retrieved from https://doi.org/10.1007/s10961-010-9154-y

Colquitt, J. A. (2001). On the dimensionality of organizational justice: a construct validation of a measure. Journal of Applied Psychology, 86(3), 386-400. Retrieved from https://doi.org/10.1037/ 0021-9010.86.3.386

Chen, Y. C., Lee, C. S., Tsui, P. L., \& Yu, T. H. (2012). Investigating organizational open innovation climate and relationships. Australian Journal of Business and Management Research, 2(5), 69-75.

DeConinck, J. B. \& Stilwell, C. D. (2004). Incorporating organizational justice, role states, pay satisfaction and supervisor satisfaction in a model of turnover intentions. Journal of Business Research, 57(3), 225-231. Retrieved from https://doi.org/10.1016/S0148-2963(02)00289-8

De Cremer, D. \& Sedikides, C. (2005). Self-uncertainty and responsiveness to procedural justice. Journal of Experimental Social Psychology, 41(2), 157-173, doi: 10.1016/j.jesp.2004.06.010.

Dobni, C. B. (2008). Measuring innovation culture in organizations: the development of a generalized innovation culture construct using exploratory factor analysis. European Journal of Innovation Management, 11(4), 539-559. Retrieved from https://doi/10.1108/14601060810911156

Dukerich, J. M., Golden, B. R., \& Shortell, S. M. (2002). Beauty is in the eye of the beholder: the impact of organizational identification, identity, and image on the cooperative behaviors of physicians. Administrative Science Quarterly, 47(3), 507-533. Retrieved from https://doi.org/10.2307/3094849

Dutton, J. E. \& Dukerich, J. M. (1991). Keeping an eye on the mirror: Image and identity in organizational adaptation. Academy of Management Journal, 34(3), 517-554. Retrieved from https://doi.org/10.5465/256405

Dutton, J. E., Dukerich, J. M., \& Harquail, C. V. (1994). Organizational images and member identification. Administrative Science Quarterly, 39(2), 239-263. Retrieved from http://dx.doi. org/10.2307/2393235

Edwards, M. R. \& Peccei, R. (2007). Organizational identification: Development and testing of a conceptually grounded measure. European Journal of Work and Organizational Psychology, 16(1), 25-57. Retrieved from http://doi.org/10.1080/13594320601088195

Fuller, J. B., Hester, K., Barnett, T., Frey, L., Relyea, L., \& Beu, D. (2006). Perceived external prestige and internal respect: New insights into the organizational identification process. Human Relations, 59(6), 815-846. Retrieved from https://doi.org/10.1177/0018726706067148

Hameed, I., Roques, O., \& Ali Arain, G. (2013). Nonlinear moderating effect of tenure on organizational identification (OID) and the subsequent role of OID in fostering readiness for change. Group \& Organization Management, 38(1), 101-127. Retrieved from https://doi.org/10.1177/1059601112472727

Haslam, S. A. (2004). Psychology in organizations: the social identity approach, 2nd ed., London: Sage. 
Hatfield, J., Robinson, R. B., \& Huseman, R. C. (1985). An empirical evaluation of a test for assessing job satisfaction. Psychological Reports, 56(1), 39-45. Retrieved from https://doi.org/10.2466/pr0.1985.56.1.39

He, H. \& Brown, A. D. (2013). Organizational identity and organizational identification: a review of the literature and suggestions for future research. Group \& Organization Management, 38(1), 3-35. Retrieved from https://doi.org/10.1177/1059601112473815

Hirst, G., van Dick, R., \& van Knippenberg, D. (2009). A social identity perspective on leadership and employee creativity. Journal of Organizational Behavior, 30(7), 963-982. Retrieved from https:// doi.org/10.1002/job.600

Hung-Wen, L. (2013). Locus of control, socialization, and organizational identification. Management Decision, 51(5), 1047-1055, doi: 10.1108/MD-11-2012-0814.

Kim, H. J., Hur, W. M., Moon, T. W., \& Jun, J. K. (2017). Is all support equal? the moderating effects of supervisor, coworker, and organizational support on the link between emotional labor and job performance. BRQ Business Research Quarterly, 20(2), 124-136. Retrieved from https://doi.org/ 10.1016/j.brq.2016.11.002

Konovsky, M. A. (2000). Understanding procedural justice and its impact on business organizations. Journal of Management, 26(3), 489-511. Retrieved from https://doi.org/10.1177/014920630002600306

Liu, Y., Perrewé, P. L., Hochwarter, W. A., \& Kacmar, C. J. (2004). Dispositional antecedents and consequences of emotional labor at work. Journal of Leadership \& Organizational Studies, 10(4), 12-25. Retrieved from https://doi.org/10.1177/107179190401000402

Mael, F. \& Ashforth, B. (1992). Alumni and their alma mater: a partial test of the reformulated model of organizational identification. Journal of Organizational Behavior, 13(2), 103-123. Retrieved from https://doi.org/10.1002/job.4030130202

Meyer, J. P., Becker, T. E., \& Van Dick, R. (2006). Social identities and commitments at work: toward an integrated model. Journal of Organizational Behavior, 27(5), 665-683. Retrieved from https://doi. org/10.1002/job.383

Muthén, L. (2004). MPlus discussion, structural equation modeling, interaction. Retrieved from www. statmodel.com/discussion/messages/11/499.html?1159825040

Naumann, S. E. \& Bennett, N. (2000). A case for procedural justice climate: Development and test of a multilevel model. Academy of Management Journal, 43(5), 881-889.

Pratt, M. G. (1998). To be or not to be: Central questions in organizational identification. in Whetten, D. A. \& Godfrey, P. (Eds), Identity in organizations: Developing theory through conversations (pp. 171-207). Thousand Oaks, CA: Sage.

Reade, C. (2001). Antecedents of organizational identification in multinational corporations: Fostering psychological attachment to the local subsidiary and the global organization. The International Journal of Human Resource Management, 12(8), 1269-1291, doi: 10.1080/09585190110083794.

Riketta, M. (2005). Organizational identification: a Meta-analysis. Journal of Vocational Behavior, 66(2), 358-384, doi: 10.1016/j.jvb.2004.05.005.

Schmidt, S. W. (2007). The relationship between satisfaction with workplace training and overall job satisfaction. Human Resource Development Quarterly, 18(4), 481-498. Retrieved from https:// doi.org/10.1002/hrdq.1216

Scott, B. A. \& Colquitt, J. A. (2007). Are organizational justice effects bounded by individual differences? an examination of equity sensitivity, exchange ideology, and the big five. Group \& Organization Management, 32(3), 290-325. Retrieved from https://doi.org/10.1177/1059601106286877

Scott, C. R., Stephens, K. K. (2009). It depends on who you're talking to. . .: predictors and outcomes of situated measures of organizational identification. Western Journal of Communication, 73(4), 370-394. Retrieved from https://doi.org/10.1080/10570310903279075

Shrout, P. E. \& Bolger, N. (2002). Mediation in experimental and nonexperimental studies: New procedures and recommendations. Psychological Methods, 7(4), 422-445. Retrieved from https:// doi.org/10.1037/1082-989X.7.4.422 
$\mathrm{OMJ}$ 17,3

Stinglhamber, F., Marique, G., Caesens, G., Desmette, D., Hansez, I., Hanin, D., \& Bertrand, F. (2015). Employees' organizational identification and affective organizational commitment: an integrative approach. PLoS One, 10(4), doi: 10.1371/journal.pone.0123955.

Tajfel, H. \& Turner, J. C. (1986). The social identity theory of intergroup behavior. in Worchel, S. \& Austin, W. (Eds), Psychology of intergroup relations (pp. 7-24). Chicago, IL: Nelson-Hall.

Taormina, R. J. (1994). The organizational socialization inventory. International Journal of Selection and Assessment, 2(3), 133-145. Retrieved from https://doi.org/10.1111/j.1468-2389.1994.tb00134.x doi: 10.1111/j.1468-2389.1994.tb00134.x.

Taylor, A. B., MacKinnon, D. P., \& Tein, J. Y. (2008). Tests of the three-path mediated effect. Organizational Research Methods, 11(2), 241-269. Retrieved from https://doi.org/10.1177/ 1094428107300344

Thibaut, J. W. \& Walker, L. (1975). Procedural justice: a psychological analysis, L. Erlbaum Associates.

Treadway, D. C., Hochwarter, W. A., Kacmar, C. J., \& Ferris, G. R. (2005). Political will, political skill, and political behavior. Journal of Organizational Behavior, 26(3), 229-245. Retrieved from https://doi.org/10.1002/job.310 doi: 10.1002/job.310.

Tyler, T. R. \& Blader, S. L. (2003). The group engagement model: Procedural justice, social identity, and cooperative behavior. Personality and Social Psychology Review, 7(4), 349-361. Retrieved from https://doi.org/10.1207/S15327957PSPR0704_07

Vijayakumar, V. S. R. \& Padma, R. N. (2014). Impact of perceived organizational culture and learning on organizational identification. International Journal of Commerce and Management, 24(1), 40-62. Retrieved from http://dx.doi.org.liblink.uncw.edu/10.1108/IJCoMA-01-2012-0003

Williams, L. J., Cote, J. A., \& Buckley, M. R. (1989). Lack of method variance in self-reported affect and perceptions of work: Reality or artifact? Journal of Applied Psychology, 74(3), 462-468. doi: 10.1037/0021-9010.74.3.462.

\section{Further reading}

Gok, S., Karatuna, I., \& Karaca, P. O. (2015). The role of perceived supervisor support and organizational identification in job satisfaction. Procedia - Social and Behavioral Sciences, 177, 38-42. Retrieved from https://doi.org/10.1016/j.sbspro.2015.02.328

May, D. R., Gilson, R. L., \& Harter, L. M. (2004). The psychological conditions of meaningfulness, safety, and availability and the engagement of the human spirit at work. Journal of Occupational and Organizational Psychology, 77(1), 11-37. Retrieved from https://doi.org/ $10.1348 / 096317904322915892$

Randall, M. L., Cropanzano, R., Bormann, C. A., \& Birjulin, A. (1999). Organizational politics and organizational support as predictors of work attitudes, job performance, and organizational citizenship behavior. Journal of Organizational Behavior, 20(2), 159-174. Retrieved from https:// doi.org/10.1002/(SICI)1099-1379(199903)20:2<159::AID-JOB881>3.0.CO;2-7

Van Knippenberg, D. \& Van Schie, E. C. M. (2000). Foci and correlates of organizational identification. Journal of Occupational and Organizational Psychology, 73(2), 137-147. Retrieved from https:// doi.org/10.1348/096317900166949

\section{Corresponding author}

Matthew Valle can be contacted at: mvalle@elon.edu

For instructions on how to order reprints of this article, please visit our website:

www.emeraldgrouppublishing.com/licensing/reprints.htm

Or contact us for further details: permissions@emeraldinsight.com 